\title{
BMJ Open Spatial barriers and the bypassing of nearby dental clinics for dental services: a secondary data analysis in Korea
}

\author{
Hosung Shin, Han-A Cho
}

To cite: Shin H, Cho H-A. Spatial barriers and the bypassing of nearby dental clinics for dental services: a secondary data analysis in Korea. BMJ Open 2019;9:e024116. doi:10.1136/ bmjopen-2018-024116

- Prepublication history for this paper is available online. To view these files, please visit the journal online (http://dx.doi. org/10.1136/bmjopen-2018024116).

Received 15 May 2018 Revised 30 0ctober 2018 Accepted 7 December 2018

Check for updates

(C) Author(s) (or their employer(s)) 2019. Re-use permitted under CC BY-NC. No commercial re-use. See rights and permissions. Published by BMJ.

Department of Social and Humanity in Dentistry, Wonkwang University School of Dentistry, Iksan, Korea (the Republic of)

Correspondence to Professor Hosung Shin; shinhosung@gmail.com

\section{ABSTRACT}

Objective This study aimed to calculate the distance patients travel to dental clinics, the rate of bypassing nearby dental clinics and the distance covered when bypassing nearby dental clinics, and explored factors associated with patients' spatial access to dental clinics. Design A secondary data analysis.

Setting Korea Health Panel.

Participants We included users of dental care services from 2008 to 2011. A total of 2375 patients and 15978 dental visits were analysed.

Primary outcome measures Korea Health Panel data (2008-2011) were used to geocode patients' and healthcare facilities' addresses. The distance travelled was calculated using road network information. To analyse the panel data, we adopted a generalised estimating equation: geographical measures on the choice of dental care facility were examined based on sex, age, educational level, equivalent income, treatment details and regional classification.

Results The median distance travelled to a dental clinic was $1.8 \mathrm{~km}$, which is farther for rural $(8.4 \mathrm{~km})$ than for urban $(1.5 \mathrm{~km})$ patients. The bypass rate was $58.9 \%$. Patients bypassing nearby dental clinics travelled 9.6 times farther for dental care $(p<0.001)$. Unlike bypass distance, travel distance was not associated with equivalent income. People with higher education and those with implants/orthodontic treatment were more likely to bypass nearby dental clinics and travelled 1.27 times and 1.17 times farther $(p<0.01)$, respectively.

Conclusions Given the spatial barrier to available dental resources, factors associated with spatial access were mostly the same between travel and bypass distance except for equivalent income. The findings of this study suggest that spatial distance acts as a utilisation barrier and demands additional opportunity cost. At the same time, patients' preferences for services also increase their willingness to bypass nearby dental clinics and travel greater distances.

\section{INTRODUCTION}

A patient's choice of healthcare facility is affected by geographical factors, ${ }^{1}$ available transportation $^{2}$ and proximity to his/her workplace $^{3}$ or residence. ${ }^{3-5}$ Spatial accessibility to healthcare services can affect health outcomes, especially those of acute illness ${ }^{3}$; however, for improving access, most attention

\section{Strengths and limitations of this study}

The study is based on nationally representative panel samples with repeated measures.

- This study first examined the distance travelled by patients to dental clinics, as well as the distance covered when bypassing nearby dental clinics in Korea.

- After geocoding a respondent's home and the dental clinic visited, the distance between them was measured using actual road network data.

- The limitation of the study is that workers who tended to choose a dental clinic near their workplace rather than their residence were excluded from the analyses as the data regarding the workplace were not available.

is directed towards aspatial aspects such as cost and health insurance. This interest is attributable to policy priority, which emphasises eliminating unmet healthcare needs related to socioeconomic gradients. ${ }^{6}$ Recent interest in the spatial analysis of health services is indebted to the development of geometric information systems and data availability and to changes in people's preferences related to healthcare outcomes, quality of care and the exercise of patient rights. ${ }^{1}$ Increased mobility in society and developments in the transportation system have expanded the travel distance for daily activities, including travel to dental clinics. ${ }^{16}$

Many reports exist on patients' bypassing of healthcare institutions when using services for childbearing, ${ }^{7}$ acute ischaemic stroke, ${ }^{8}$ mammography examinations, ${ }^{9}$ radiation therapy for cancer, ${ }^{10}$ HIV treatment, ${ }^{11}$ haemodialysis $^{12}$ and so on. Studies on the topic assume that the nearest healthcare facility is bypassed in favour of one with a superior quality of healthcare. ${ }^{13}$ Bypass is the distance from the nearest provider or facility to another provider or facility that is beyond the defined threshold used in each study; this distance is used as a measure of geographical accessibility. ${ }^{14}$ Studies ${ }^{15}$ report that patients 
bypass primary healthcare facilities because of their perceptions of size, lack of specialty care and limited services. Melcher et $a l^{16}$ also found that patients bypassed local hospitals in rural areas because of the unavailability of desired healthcare services, use of healthcare facilities close to their workplace in an urban area, previous experience of bypassing rural hospitals and quality assurance.

Few studies have investigated the bypassing of dental care facilities. ${ }^{1415}$ McKernan $e t ~ a l^{14}$ reported that the rate of dentist bypass was $76.8 \%$. With consent from the Korea Institute for Health and Social Affairs (Sejong, South Korea), in this study we used data from 2008 to 2011 Korea Health Panel (KHP; Sejong, South Korea) ${ }^{17}$ to examine travel and bypass distance to dental care facilities and to determine factors associated with travel distance to a dental clinic and bypassing the nearest dental facilities. Distance travelled to a dental facility in this context refers to the patient's preferred dental care facility and use of dental care, and in Khan's terms, involves 'realised spatial' accessibility. ${ }^{18}$

\section{METHODS}

\section{Study population and data collection}

The KHP is a national panel survey established in 2008 with 7866 nationally representative households in South Korea. The same questionnaires are administered to the same households annually. In 2011, the retention rate of the KHP was $69.2 \% .{ }^{17}$ The KHP collects information on healthcare expenditures, patterns and types of healthcare service utilisation and factors, such as demographics, health status, income and health behaviour, influencing utilisation and consumption patterns. The KHP employs the South Korea Population and Housing Census (Seoul, South Korea) as its sampling frame to maintain national representativeness. For population-level analysis, resident type, sex and home ownership are used as variables. Sample households are chosen using probability proportional to the size and a stratified cluster sampling method. For our analysis, we used KHP data for 2008-2011. The individuals in this analysis were users of dental care services who received care at least once during the study period. A total of 2375 patients and 15978 dental visits were analysed.

\section{Configuration of the variables}

Spatial barriers to healthcare utilisation imply limited geographical accessibility due to an imbalance of the spatial distribution of healthcare institutions. Spatial barriers are often measured in terms of travel distance, ${ }^{5} 19$ transportation availability ${ }^{19}$ and time travelled. ${ }^{5}{ }^{19}$ In this study, we chose to measure the travel distance to evaluate spatial barriers to dental care utilisation. To measure the distance travelled to a dental clinic (ie, travel distance), we used digital administrative district maps provided by Statistics Korea (Daegu, South Korea) ${ }^{20}$ and the digital transportation map provided by the Korea Transport Database (Sejong, South Korea). ${ }^{21}$ Using network analysis, we calculated the distances from a dental service user's residence to the dental clinic nearest the user's residence and from the user's residence to the dental clinic they actually used. This allowed us to measure the shortest distance to a dental clinic. The road network used in this study was delimited to local expressways, state-supported local roads, local roads, city expressways and general local roads with 2.8 lanes (range 1-16 lanes) on average.

To obtain the distance measurement, the addresses of patients' residences and dental clinics were geocoded; then, the geocodes were combined through network analysis based on digital geographical maps and traffic network maps. 'Bypass distance' was the distance from the nearest dental clinic to the dental clinic actually used. In this case, the bypass distance was defined as the distance between two dental clinics exceeding a $500 \mathrm{~m}$ threshold. The $500 \mathrm{~m}$ threshold is the distance travelled in approximately $15 \mathrm{~min}$ by foot. Within the distance threshold, the difference was insignificant for dental clinic use because it included the radius of daily activity and shared market area. ${ }^{14}$ Figure 1 shows the typical bypass of the nearest dental clinics. Patients who lived in an urban district (eg, Seocho District) bypassed nearby dental clinics (indicated by blue triangles in figure 1) and visited their preferred dental clinics (indicated by red circles in figure 1), including clinics beyond the district border.

Our independent variables were sex, age, educational level, equivalent income, administrative district classification, treatment details and study period (2008-2011). Patients, aged 20-44 years, were the reference group. The remaining patients were divided into two age groups: $45-65$ years and $>65$ years. Educational levels were elementary school or lower, middle school and high school, and college and/or enrolled in higher education. Equivalent income was calculated by dividing the total household annual income by the square root of the family size. To evaluate the degree of urbanisation, which was often related to the density of regional dental resources (eg, the number of dental professionals and facilities), we categorised 251 municipalities in South Korea into three types: urban district, mid-to-small city and rural county. We used the municipality variable as a proxy of unequal distribution of dental resources because of the positive relationship between population size and dental resource distribution at the municipal level in South Korea. We classified dental treatments into three types: prosthetics (including dentures), implants and orthodontic services, and others. Most prostheses and implants/orthodontics are not covered by the National Health Insurance (NHI; Seoul, South Korea). Patients are instead expected to pay the entire cost of these services. To account for variations in the use of dental care services during the survey period, the model included categorical year terms.

Figure 2 displays the geographical distribution of the patients and dental clinics. The density and proximity of dental clinics to the respondents' residences are delineated in urban districts, small cities and rural areas. Dental clinics were highly concentrated in urban districts 


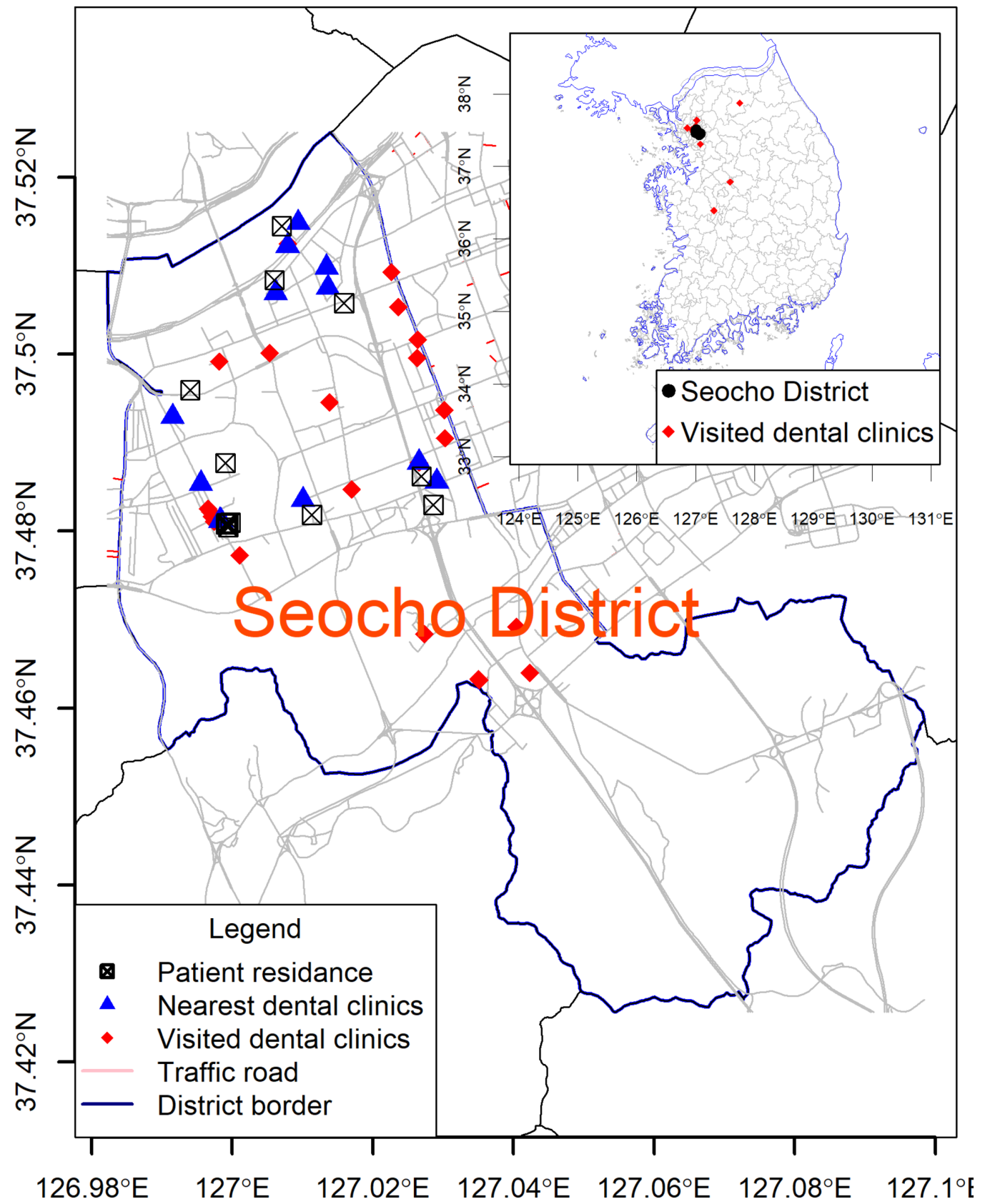

Figure 1 The maps display bypass of the nearest dental clinics.

(upper right), whereas they were sparse in rural counties (lower right).

\section{Statistical analysis}

The KHP dataset tended to show intraindividual correlations owing to repeated measurements. ${ }^{22}{ }^{23}$ During the 4-year study period, individuals used dental care 1-110 times. The panel data analysis methods used can generally be divided into a 'subject-specific' model and a 'population-averaged' model. The former explicitly shows heteroscedasticity among the subjects, while the latter is a function of covariates without considering explicit heteroscedasticity. Random-effects models are used to estimate subject-specific effects, while the generalised estimating equations (GEEs) method is usually used to provide population-averaged effects. ${ }^{23}$ In this study, we employed the population-averaged GEE method, which identifies the average variation of dependent variables in a population rather than the individual's level of change. ${ }^{24}$ The travel distance was skewed positively; we log-transformed the dependent variables in preparation for GEE regression analysis and employed identity as the link function and Gaussian as the family in the GEE. The coefficients of GEE regression represent logged values and were exponentially transformed for readability. GRASS GIS 7 (GRASS Development Team, Open Source Geospatial Foundation. http://grass. osgeo.org) was used to measure the bypass and travel distances, and R V.3.3.4 for Windows (R Foundation 

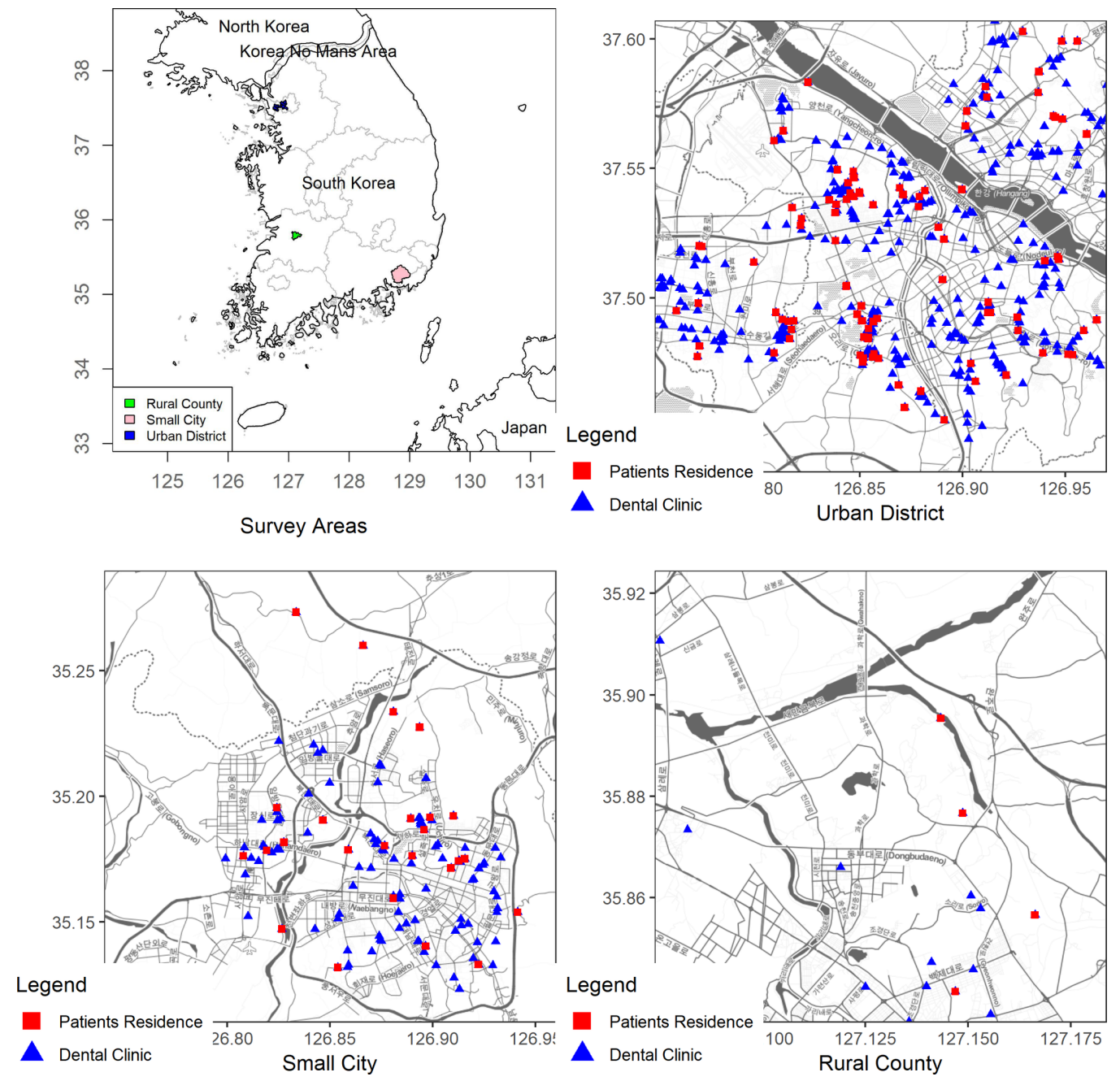

Figure 2 Distribution of dental resources by geographical area.

for Statistical Computing, Vienna, Austria) was used for statistical analyses.

\section{Patient and public involvement statement}

The requirement for obtaining informed consent from subjects was waived because of the study's secondary analysis of KHP data.

\section{RESULTS}

\section{Subject characteristics}

Table 1 shows the distribution of frequency of visits and distance to dental clinics based on the respondents' characteristics. Women used more dental services than men. Individuals $>65$ years accounted for approximately $38 \%$ of the total dental care services used, and $34 \%$ of the respondents were elderly. Patients whose educational level was lower than middle school accounted for nearly a quarter of the visits (4174 visits). Distance travelled to dental clinics varied based on the type of dental services. More than four-sixths of dental visits were by urban district residents.
Distance travelled to dental clinics and bypass status

For distance measured, it was necessary to consider the outliers because they denoted unusual encounters. For this reason, we reported the median distance with the mean value. The mean distance travelled to dental clinics was $9.41 \mathrm{~km}$, approximately $1 \mathrm{~km}$ farther than the bypass distance. This implied that the mean distance from the nearest dental clinic to a respondent's residence was $1 \mathrm{~km}$ in the study population. The mean travel distance was significantly higher for people who were 20-44 years, had a college education, used implant/orthodontics and prosthetics and were rural residents.

The patterns of the bypass and travel distance were similar. Compared with other respondents, those with the highest education travelled more than $5 \mathrm{~km}$ farther to dental clinics and also travelled approximately twice the bypass distance as compared with patients with middle/ high school education. Patients with non-covered services (eg, implants/orthodontics, dental prostheses) were more likely to bypass the nearest dental clinic and travel farther than patients with NHI-covered dental services. However, rural respondents were more likely to travel farther to dental clinics, compared with other respondents, whereas 
Table 1 Travel and bypass distance based on subjects' characteristics and region

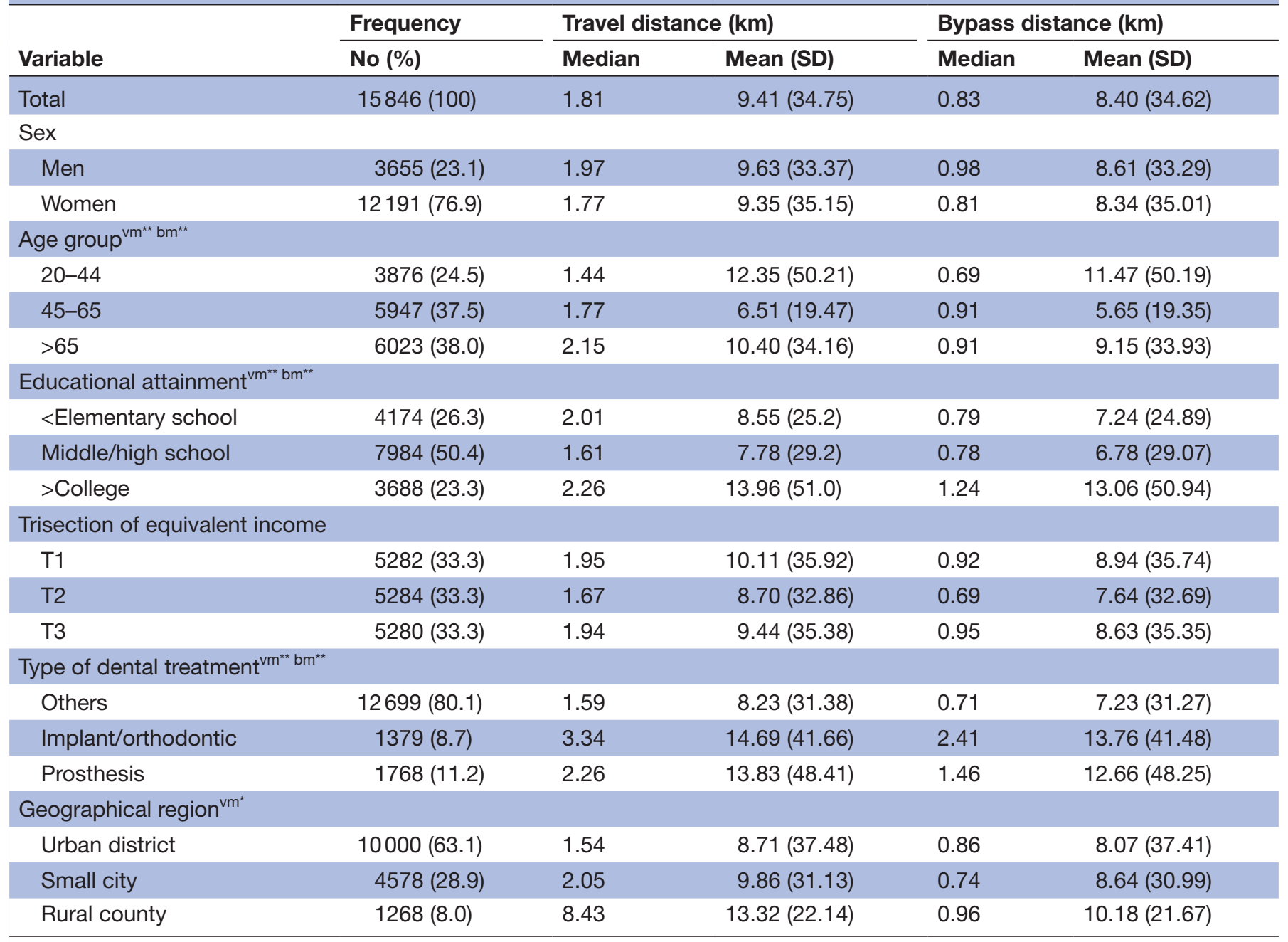

${ }^{*} \mathrm{P}<0.05 ;{ }^{* *} \mathrm{P}<0.001$.

$\mathrm{bm}$, mean of the bypass distance; vm, mean of the visit distance.

the bypass distance was not significantly different. For example, the difference in travel distance was more than $4 \mathrm{~km}$ between rural and urban district respondents, but the difference in bypass distance was only approximately $2 \mathrm{~km}$.

Income level measured by equivalent income was not significantly associated with travel and bypass distance. For dental service utilisation, the poorest group travelled and bypassed farther distances than the highest income group, but the middle-income group travelled and bypassed the shortest distances. Sex was not associated with the distance travelled or with bypassing the nearest dental clinics.

The mean bypass rate was $58.9 \%$ (ie, every four of six visits was a bypass visit). Bypass rates were not significantly different by geographical region $(\mathrm{p}=0.183)$. The rates of dental clinic bypass were $59.6 \%, 58.1 \%$ and $58.0 \%$ in urban districts, small cities and rural counties, respectively. Most (95.7\%) dental clinics in urban districts were within $2 \mathrm{~km}$ of a subject's residence, compared with approximately $59 \%$ of clinics in rural county areas. More than
$27 \%$ of rural dental clinics were $>5 \mathrm{~km}$ from a subject's residence, compared with just $0.4 \%$ in urban districts. In urban areas, the greater the distance to the nearest dental clinic, the greater the tendency to bypass. However, rural areas tended to have the highest distance travelled at the middle distance $(2-5 \mathrm{~km})$ (figure 3$)$.

\section{Effect of respondents' characteristics on distance travelled to} a dental clinic and bypassing the nearest dental clinic

Bypassing the nearest dental clinic was associated with travel distance over nine times farther $(p<0.001)$. The distance travelled by patients $45-65$ years and $>65$ years was 1.26 times $(\mathrm{p}<0.05)$ and 1.37 times $(\mathrm{p}<0.05)$, respectively, that of the reference group (ie, respondents 20-44 years). College graduates travelled 1.27 times $(\mathrm{p}<0.05)$ farther than high/middle school respondents. Equivalent income was not associated with the distance travelled to dental clinics. Compared with urban district residents, small city residents and rural county residents travelled 1.25 times $(\mathrm{p}<0.05)$ and 1.98 times $(\mathrm{p}<0.001)$ farther, respectively. The distance travelled to dental 


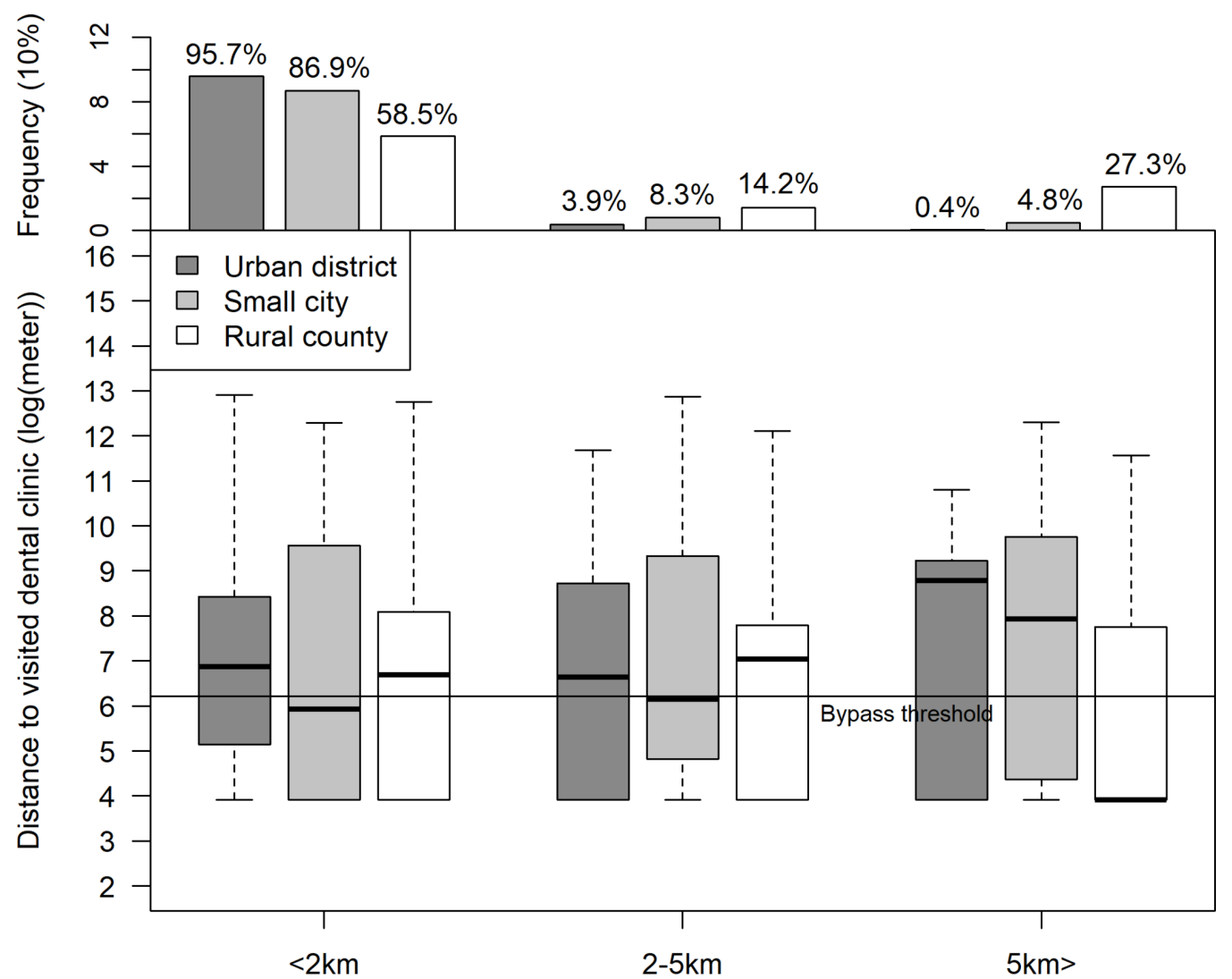

Distance to the nearest dental clinic

Figure 3 Travel distance to dental clinic and bypass rates by distance to the nearest dental clinic.

clinics increased approximately 1.17 times $(\mathrm{p}<0.05)$ for implant/orthodontic services compared with covered dental services. However, prostheses users did not statistically differ from the reference group (table 2).

Some characteristics of the respondents were associated with bypass distance, but the patterns differed. Household equivalent income inversely affected bypass but not travel distance. Low-income respondents travelled farther beyond the nearest dentists compared with higher income groups. Unlike travel distance, there was no significant difference between rural and urban respondents in bypass distance. This could be attributed to the fact that the bypass distance was not large and the distance to the nearest dental clinics was far greater for rural than for urban respondents. Respondents seeking implants and orthodontic services were more likely to bypass the nearest dental clinics and travel farther than the reference group.

\section{DISCUSSION}

Using KHP data for 2008-2011, we examined factors associated with to what extent respondents bypassed the nearest clinics when they required dental services. Our results showed that the distance travelled to dental clinics was greater for the older age group, respondents with college and higher education, respondents in rural areas and for dental services not covered by the NHI. The rate of bypassing the nearest dental clinics was approximately $60 \%$; the rate did not differ between geographical regions. Bypassing the nearest dental clinics was associated with age, educational attainment, equivalent income, geographical region and type of dental service.

The bypass rate in this study was lower than that of a dental study ${ }^{14}$ in the USA. The reason for the lower rate in this study was the density of dentists per unit area and the difference in the dental care delivery system. The density of dentists per 1000 people in the USA (0.6) is higher than that in South Korea $(0.43)^{25}$; however, the number of dentists per unit area in South Korea is greater than that in the USA, which suggests that South Korean patients are more likely to travel shorter distances than patients in the USA. Additionally, dental specialty licences have only recently been introduced in South Korea; therefore, referring patients to specialists has not yet been widely adopted.

Education and income are traditionally key factors in the use of healthcare services. Income has a considerable impact on dental care utilisation. Based on regression analysis, income had no consistent association with spatial distance, whereas educational level (especially a higher level such as attending college and advanced study) had a significant association with farther travel and bypass distance. We previously found that patients who had attained a higher level of education (ie, above college) 
Table 2 Results of GEE analysis, including variables associated with distance

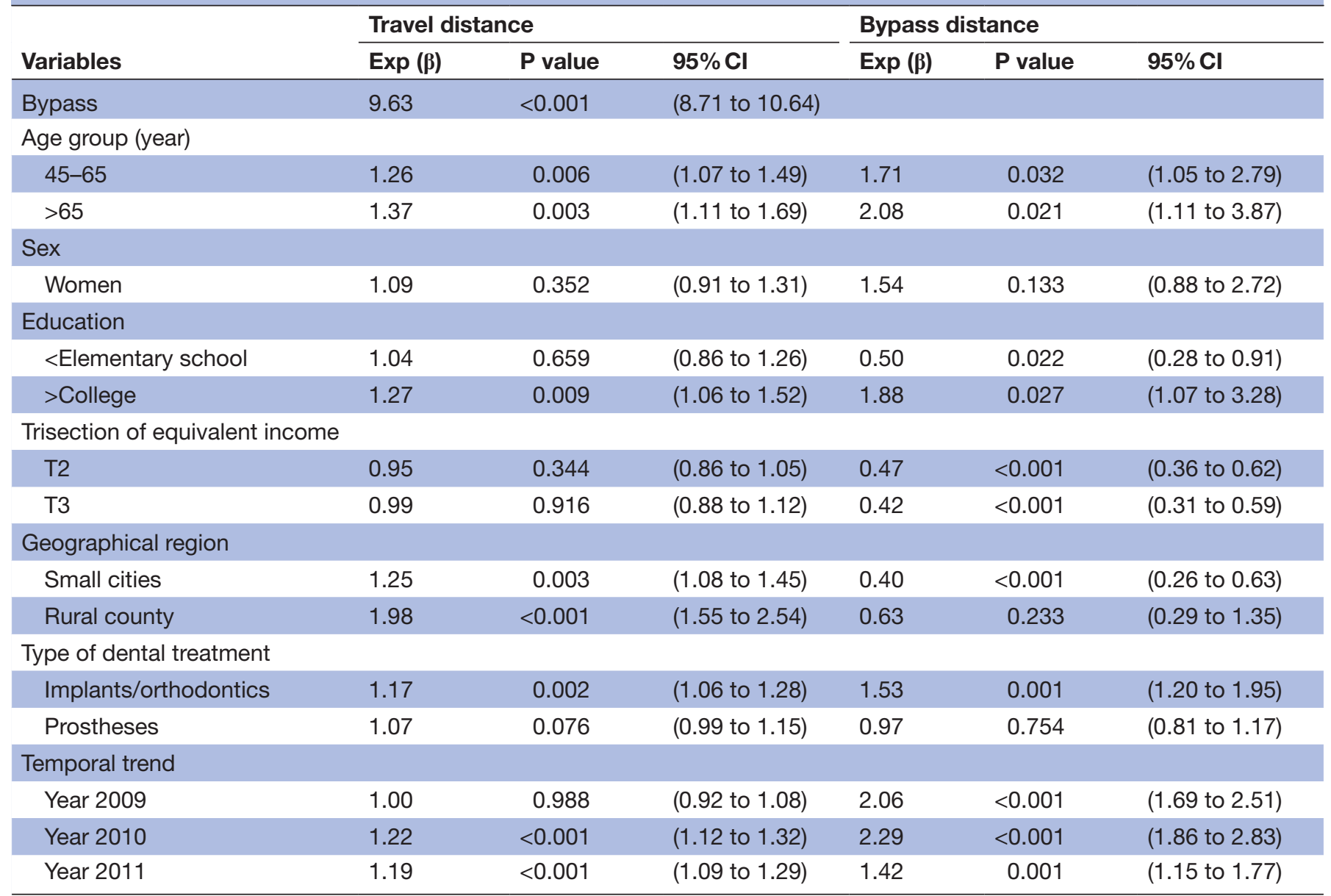

The dependent variable was log-transformed.

Exp ( $\beta$ ), exponentiation of coefficient; $\beta$, coefficient of generalised estimating equation regression.

GEE, generalised estimating equation.

visited healthcare facilities that were approximately $2.7 \mathrm{~km}$ farther away from their residence than did those with lower educational attainment. ${ }^{26}$ These findings indicated that the inconvenience of travel, opportunity cost and time spent travelling could be offset by the satisfaction gained by the use of self-selected dental care services.

The relationship of income with spatial accessibility is inconclusive. Our study showed that income had no effect on the travel distance but had an inverse relationship with bypass distance. This finding could be attributed to the fact that dental resources were more densely located in affluent areas. A patient's willingness to travel a greater distance to a dental clinic for preferred services was similar between poor and rich patients, but the bypass distance of rich patients was shorter than that of the poor patients because of the unequal distribution of dental resources, which favours the rich. Additionally, NHI-covered basic dental services are provided to all citizens, and the out-ofpocket expenses of basic dental services are affordable for the poor. For example, in a study in the USA, low income was a predictor of increased travel distance when using medical/dental care services ${ }^{27}$ and orthodontic care in rural low-income children ${ }^{28}$ and a predictor of higher bypass distance. ${ }^{14}$ However, a study conducted in the UK reported that travel distances increased with higher income levels. ${ }^{29}$ The reason for the reverse impact of income on travel distance to dental clinics in these studies may be because of differences in the dental insurance systems in the two countries.

Travel distance to healthcare facilities impacts several areas. A distance-decay model noted that increased travel distances to healthcare facilities generally impeded the proper use of healthcare services. ${ }^{30}$ Furthermore, the disproportionate distribution of dental resources constitutes a spatial barrier that can demand greater travel distances, and thus affect transportation and opportunity costs. ${ }^{31}$ Rural residents, ${ }^{52}$ the elderly ${ }^{16}$ and people with conditions ${ }^{1}$ tended to be willing to travel longer distances. Moreover, patients' perceptions that influenced their willingness to travel longer distances encompassed their level of involvement in decisions about their condition/ illness or treatment, the reputation of the provider and the convenience in scheduling. ${ }^{133}$

Travel distances for prosthetics (including dentures), implants and orthodontic treatments not covered by the NHI were longer than travel distances for general 
conservative and periodontal services. A respondent's effort and wish to receive acceptable non-covered dental services was largely proportionate to the cost, and it increased his/her willingness to travel greater distances. Thus, nearby and distant dental clinics were both included in a resident's potential travel range. However, respondents using expensive dental services were more likely to bypass nearby dental clinics. Impedance such as travel and bypass distance were no longer barriers for these acceptable dental services.

Our regression findings revealed that travel and bypass distances were shorter in younger adults (20-44years) than in the elderly. This finding was inconsistent with previous studies ${ }^{16}$ in which younger groups travelled farther than the elderly for healthcare. For example, the Department for Transport in the UK reported that adults 30-39 years and 50-64 years annually travelled 9335 miles and 7865 miles, respectively, compared with 1794 miles for adults $65-79$ years. ${ }^{34}$ In our study, patients $>65$ years travelled 1.37 times as far as patients 20-44 years. We believe this is associated with a previous finding ${ }^{35}$ that the elderly are largely poor and unemployed, and thus use their money more carefully. They also receive non-covered services more often than the reference group because they have poorer oral health than the reference group; these factors force the elderly to travel farther for acceptable treatments.

\section{CONCLUSION}

With the repeatedly measured KHP data, we could analyse the mode of a distance of travel and bypass to a dental clinic and examine the factors associated with spatial distance. The limitation of this study is that workers who tend to choose a dental clinic near their workplace rather than one near their residence were excluded from the analyses as the KHP did not provide data regarding the workplace. Second, the travel time was not analysed. The travel distance is generally proportional to the travel time, but may vary depending on the traffic situation. Especially in urban areas, travel time and distance are not likely to be proportional. Lastly, since the KHP data only listed the type of dental care provided, we could not include detailed information regarding the characteristics of the chosen dental clinics, such as their quality, prices, availability of services or other factors that might explain the respondent's choice of dental clinic.

Our findings suggest that the distances respondents travelled to visit dental clinics reflected the range of distances they considered acceptable to travel for personal care purposes, and differed depending on the specific dental treatment and sociodemographic characteristics. Bypassing is costly and inefficient for the individuals and the health system ${ }^{36}$ and is seen as a powerful expression of a patient's preference, lack of service variety, obsolete equipment and perceived poor quality. ${ }^{37}$ To ensure that patients receive timely and accessible high-quality services, the health system provides relevant information to help them seek healthcare institutions and professionals. Governmental policies that provide incentives for dentists to set up clinics in areas where dental resources are lacking are also required. Then, dentists can consider providing practical benefits to patients with large bypass distances, for example, by ensuring that the appointment time is strictly adhered to and by providing support for transportation costs based on the time and distance travelled.

Acknowledgements We would like to show our gratitude to the Korea Institute for Health and Social Affairs (Sejong, South Korea) and Korean National Health Insurance Service (Seoul, South Korea) for the use of the restricted KPS dataset.

Contributors HS: conception and design of the study, analysis and interpretation of data, drafting the manuscript and revising the manuscript critically for important intellectual content. H-AC: literature review, interpretation of data and drafting the manuscript. Both authors have read and approved the final draft of the manuscript.

Funding This work was supported by the Korea Ministry of Environment (grant No. 412-111-001) and Korea Ministry of Environment as Climate Change Correspondence Program (project number: 2014001310007).

Competing interests None declared.

Patient consent for publication Not required.

Provenance and peer review Not commissioned; externally peer reviewed.

Data sharing statement No additional data are available.

Open access This is an open access article distributed in accordance with the Creative Commons Attribution Non Commercial (CC BY-NC 4.0) license, which permits others to distribute, remix, adapt, build upon this work non-commercially, and license their derivative works on different terms, provided the original work is properly cited, appropriate credit is given, any changes made indicated, and the use is non-commercial. See: http://creativecommons.org/licenses/by-nc/4.0/.

\section{REFERENCES}

1. Exworthy M, Peckham S. Access, choice and travel: implications for health policy. Social Policy and Administration 2006;40:267-87.

2. Whetten R, Whetten K, Pence BW, et al. Does distance affect utilization of substance abuse and mental health services in the presence of transportation services? AIDS Care 2006;18:27-34

3. Brondeel R, Weill A, Thomas F, et al. Use of healthcare services in the residence and workplace neighbourhood: the effect of spatial accessibility to healthcare services. Health Place 2014;30:127-33.

4. Mooney C, Zwanziger J, Phibbs CS, et al. Is travel distance a barrier to veterans' use of VA hospitals for medical surgical care? Soc Sci Med 2000;50:1743-55.

5. Probst JC, Laditka SB, Wang J-Y, et al. Effects of residence and race on burden of travel for care: cross sectional analysis of the 2001 US National Household Travel Survey. BMC Health Serv Res 2007;7:40.

6. Guagliardo MF. Spatial accessibility of primary care: concepts, methods and challenges. Int J Health Geogr 2004;3:3-13.

7. Salazar M, Vora K, Costa AD. Bypassing health facilities for childbirth: a multilevel study in three districts of Gujarat, India. Glob Health Action 2016;9:32178.

8. Ahuja C, Mamdani M, Saposnik G. Stroke outcomes research Canada working group for the sorc working. influence of socioeconomic status on distance traveled and care after stroke. Stroke 2012;43:233-5.

9. Alford-Teaster J, Lange JM, Hubbard RA, et al. Is the closest facility the one actually used? An assessment of travel time estimation based on mammography facilities. Int J Health Geogr 2016;15:8.

10. Ward MM, Ullrich F, Matthews K, et al. Where do patients with cancer in lowa receive radiation therapy? J Oncol Pract 2014;10:20-5.

11. Akullian AN, Mukose A, Levine GA, et al. People living with HIV travel farther to access healthcare: a population-based geographic analysis from rural Uganda. J Int AIDS Soc 2016;19:20171.

12. Saunders MR, Lee $\mathrm{H}$, Maene $\mathrm{C}$, et al. Proximity does not equal access: racial disparities in access to high quality dialysis facilities. $J$ Racial Ethn Health Disparities 2014;1:291-9.

13. Roh C-Y. Health care utilization by rural patients: what influences hospital choice? Soc Work Public Health 2007;23:75-94. 
14. McKernan SC, Pooley MJ, Momany ET, et al. Travel burden and dentist bypass among dentally insured children. J Public Health Dent 2016;76:220-7

15. Visser CA, Marincowitz GJO, Govender I, et al. Reasons for and perceptions of patients with minor ailments bypassing local primary health care facilities. South African Family Practice 2015;57:333-6.

16. Melcher J, Glenn J, Chiles L, et al. The rural health care challenge. staff report to the Special Committee on Aging, United States Senate. US: Government Printing Office, 1988.

17. Korea Health Panel. Korea institute for health and social affairs and national health insurance service: Korea Health Panel, 2008.

18. Khan AA. An integrated approach to measuring potential spatial access to health care services. Socioecon Plann Sci 1992;26:275-87.

19. Syed ST, Gerber BS, Sharp LK. Traveling towards disease: transportation barriers to health care access. J Community Health 2013;38:976-93.

20. Statistics Korea. District digital maps. 1996 http://kostat.go.kr/portal/ eng/index.action

21. Korea Transport DataBase. Digital transportation map: The Korea Transport Institute, 2016. https://www.ktdb.go.kr/eng/index.do.

22. LIANG K-YEE, Zeger SL. Longitudinal data analysis using generalized linear models. Biometrika 1986;73:13-22.

23. Zeger SL, Liang KY, Albert PS. Models for longitudinal data: a generalized estimating equation approach. Biometrics 1988;44:1049-60.

24. Hu FB, Goldberg J, Hedeker D, et al. Comparison of populationaveraged and subject-specific approaches for analyzing repeated binary outcomes. Am J Epidemiol 1998;147:694-703.

25. OECD. Organisation for Economic Co-operation and Development (OECD). Health care resources : dentists. 2018 http://stats.oecd.org/ index.aspx?queryid $=30177$

26. Shin H-S, Lee S-H. Factors affecting spatial distance to outpatient health services. Korean $\mathrm{J}$ of Health Policy and Administration 2011:21:23-43.
27. Probst JC, Laditka SB, Wang JY, et al. Mode of travel and actual distance traveled for medical or dental care by rural and urban residents. South Carolina Rural Health Research Center 2006.

28. McKernan SC, Kuthy RA, Momany ET, et al. Geographic accessibility and utilization of orthodontic services among medicaid children and adolescents. J Public Health Dent 2013;73:56-64.

29. Hine J, Kamruzzaman M. Journeys to health services in great Britain an analysis of changing travel patterns 1985-2006. Health Place 2012;18:274-85.

30. Starmans B, Leidl R, Rhodes G. A comparative study on crossborder hospital care in the Euregio Meuse-Rhine. The European $\mathrm{J}$ of Public Health 1997;7:33-41.

31. Kikwilu EN, Masalu JR, Kahabuka FK, et al. Prevalence of oral pain and barriers to use of emergency oral care facilities among adult Tanzanians. BMC Oral Health 2008;8:28.

32. Bhagavatula $P$, Xiang $Q$, Szabo A, et al. Rural-urban differences in dental service use among children enrolled in a private dental insurance plan in Wisconsin: analysis of administrative data. BMC Oral Health 2012;12:58.

33. Lawrence Z. Building on the best-choice, responsiveness and equity in the NHS. Health Expect 2004;7:176-9.

34. Department of the Environment.. Transport and the regions. social exclusion and the provision and availability of public transport: Transport Research Laboratory, 2000.

35. Lee S. Income composition and expenditure inequality of the elderly household by income classes. J Popul Assoc Korea 2015;38:85-111.

36. Kruk ME, Mbaruku G, McCord CW, et al. Bypassing primary care facilities for childbirth: a population-based study in rural Tanzania. Health Policy Plan 2009;24:279-88.

37. Barnett PG, Hong JS, Carey E, et al. Comparison of accessibility, cost, and quality of elective coronary revascularization between veterans affairs and community care hospitals. JAMA Cardiol 2018;3:133-14. 